\title{
CONTROLE ALTERNATIVO DE NEMATOIDE DAS GALHAS (Meloidogyne enterolobii) COM CRAVO DE DEFUNTO (Tagetes patula L.), INCORPORADO AO SOLO
}

\author{
F. J. C. MOREIRA ${ }^{1^{*}}$ e A. C. S. FERREIRA ${ }^{2}$ \\ ${ }_{1}^{1}$ Instituto Federal do Ceará - IFCE \\ ${ }^{2}$ Empresa de Assistência Técnica e Extensão Rural do Ceará - EMATERCE \\ franze.moreira@ifce.edu.br
}

Artigo submetido em agosto/2013 e aceito em fevereiro/2015

DOI: $10.15628 /$ holos. 2015.1600

\section{RESUMO}

A correta identificação de fitopatógenos é de grande importância para se formar um acervo de dados que serão úteis para diagnose e controle. Com o aumento do plantio de goiaba no Ceará, percebe-se a presença de Meloidogyne associado à cultura e causando grandes prejuízos, contudo, o controle para tal moléstia ainda não existe. Em função disso, objetivou-se nesse ensaio avaliar o controle alternativo de $M$. enterolobii com a incorporação de fitomassa de cravo de defunto. O trabalho foi realizado de janeiro a maio de 2009, em Barbalha - CE. A avaliação do efeito da incorporação da fitomassa de cravo de defunto ao solo foi realizada em função da idade de transplantio $(12,18,24$ e 30 dias). Avaliou-se aos 35 dias após o transplantio do tomate, sendo mensuradas: número de galhas, peso fresco da parte aérea e do sistema radicular. Verificou-se que a incorporação da fitomassa de cravo de defunto ao solo apresentou-se eficiente na redução da população do nematoide. Conclui-se que a incorporação de fitomassa é eficiente na redução populacional de $M$. enterolobii e que 30 dias após o transplantio é a melhor época para se cortar e incorporá-la ao solo.

PALAVRAS-CHAVE: Nematoide das galhas, rotação de culturas, manejo sustentável, Meloidogyne enterolobii

\section{ALTERNATIVE CONTROL OF ROOT-KNOT NEMATODES (Meloidogyne enterolobii) WITH MARIGOLD (Tagetes patula L.) INCORPORATED IN SOIL}

\begin{abstract}
The accurate identification of pathogens is of great importance to form a data archive that will be useful for diagnosis and control. With the increased planting of guava in Ceará, one notices the presence of Meloidogyne associated with culture and causing major damage, however, control for this disease does not exist yet. As a result, this trial aimed to evaluate the alternative control of $M$. enterolobii with the incorporation of biomass of marigold. The study was conducted from January to May 2009 in Barbalha - CE. The effect of the incorporation of the dry weight of
\end{abstract}

marigold to the soil was performed according to age at transplanting (12, 18, 24 and 30 days). We evaluated 35 days after transplanting the tomato, being measured: the number of galls, fresh weight of shoot and root system. It was found that the incorporation of the dry weight of marigold showed the soil to be effective in reducing the nematode population. We conclude that the incorporation of biomass is effective in reducing populations of $M$. enterolobii and 30 days after transplant is the best time to cut and incorporate it into the ground.

KEYWORDS: root-knot nematodes, crops rotation, Meloidogyne enterolobii 


\section{INTRODUÇÃO}

Atualmente o Brasil está entre os três maiores pólos produtores mundiais de frutas, com mais de 47,6 milhões de toneladas produzidas ao ano em 3,10 milhões hectares plantados no ano de 2012 , o que representa $6,5 \%$ da produção mundial, segundo dados da FAO (ADECE, 2013). Estamos atrás apenas da China e da Índia. $O$ incremento na produção tem se mantido em torno de 4,5\% ao ano. Mesmo com produção elevada, uma reduzida quantidade de frutas é destinada a exportação, pois a grande maioria é designada basicamente ao consumo interno, com consumo per capita de frutas de $57 \mathrm{Kg} \cdot \mathrm{Kno}^{-1}$ (ADECE, 2013). Além da parte comercial, a fruticultura destaca-se como atividade geradora de renda, fixadora de mão-de-obra no campo e adequada como cultura alternativa para pequenos produtores rurais.

A goiaba (Psidium guajava L.), pertencente à Família Myrtaceae, a qual encerra um grande número de espécies frutíferas, tem suas origens nos trópicos americanos, e é distribuída hoje ao longo das áreas tropicais e subtropicais do mundo. Segundo o ADECE (2013) os quatro principais produtores de goiaba do mundo em 2012 foram: a Índia, o Paquistão, o México e o Brasil.

Segundo a ADECE (2013) o Brasil produziu em 2011, 342.528 toneladas, numa área de 15.917 hectares, sendo que a região Nordeste foi a que mais produziu com 156.886 de toneladas, seguida da região sudeste com 142.200 toneladas. O estado do Ceará participa, ainda timidamente, ao montante produzido, pouco superior a 7,0\% (11.264 ton.) da produção nordestina.

Contudo, a produção desta fruteira vem sendo drasticamente reduzida, principalmente no Nordeste, em função da presença de muitas pragas e doenças que acometem a cultura, com destaque para os nematoides. Muitas de suas espécies, principalmente as do gênero Meloidogyne, são importantes na agricultura como fitopatógenos, que promovem a destruição do sistema radicular, a partir da liberação de substâncias que induzem a formação de nodulações ou lesões necróticas nas raízes, impedindo as plantas de absorverem água e nutrientes, prejudicando assim seu desenvolvimento e consequentemente o potencial produtivo da cultura. (Lordello, 1992; Tihohod, 1993; Freitas et al. 2004; Ferraz et al., 2010).

Vários são os problemas fitossanitários associados ao solo que acometem as fruteiras, destacando-se em algumas os nematoides das galhas. Por permanecerem, na maioria das vezes, em ambientes com alta densidade de plantas e por serem produzidas em substratos não submetidos a um tratamento para eliminação de patógenos de solo, como, os fungos Pythium spp., Phytophthora spp., os nematoides como Meloidogyne spp., Pratylenchulus spp. e bactérias como Ralstonia spp., entre outras (Lordello, 1992; Tihohod, 1993; Ferraz et al., 2010). A ocorrência desses agentes pode resultar em sérios prejuízos, e dependendo do tipo e intensidade, pode constituir-se em fator limitante para cultura.

No Brasil, os nematoides formadores de galhas, são considerados os principais responsáveis por perdas expressivas nas culturas, sejam elas graníferas, oleaginosas, frutíferas e ornamentais, e principalmente em regiões com predominância de elevadas temperaturas, fator que favorece a manifestação do parasitismo, em razão do maior número de ciclos reprodutivos 
que estes produzem em curto espaço de tempo (Lordello, 1992; Tihohod, 1993; Freitas et al., 2004).

Segundo Campos et al. (1998) o controle químico de nematoides além de apresentar custos elevado, geralmente é pouco efetivo e pode deixar resíduos nos alimentos, prejudicando a saúde humana e o meio ambiente. Em vista disso, esforços têm sido concentrados na integração de agentes de controle biológico e outras estratégias de manejo menos agressivas ao ambiente para o controle dos nematoides.

Estudos do efeito de extratos botânicos com ação nematicidas estão sendo evidenciados e, dentro deste contexto, algumas plantas têm apresentado um grande potencial como matériaprima para produção de nematicidas naturais (Neves et al., 2005).

Diferentes espécies vegetais já foram estudadas quanto à possibilidade de serem usadas no controle de nematoides. Maior atividade nematicida sobre juvenis de $M$. incognita foi observado em macerados de mentrasto (Ageratum conyzoides L.), bardana (Arctium lappa L.), Artemísia (Artemisia vulgaris L.), losna (Artemisia absinthium L.), confrei (Symphytum officinale L.) e catinga de mulata (Tanacentum vulgare L.), (Dias et al, 2000). Óleo de mostarda (Sinapsis alba L.) e dois produtos à base de capsaicina, capsainídes e alil isotiocianato testados, na concentração mais baixa (5,0\%) reduziram a eclosão em 90 \% juvenis $\mathrm{J} 2$ de $M$. javanica (Neves et al., 2005). Este resultado é interessante, pois os juvenis $J 2$ representam o estágio em que são responsáveis pela entrada nos tecidos da planta hospedeira, onde o mesmo viverá como endoparasita sedentário, denominados também nesta fase de estádio infestante. Óleos essenciais foram eficientes na inibição da eclosão de juvenis J2 de Meloidogyne incognita raça 2 (Moreira et al., 2009). Campos et al., (2001), conseguiram redução expressiva na inibição da eclosão de juvenis $\mathrm{J} 2$ de $M$. incognita, quando estes foram tratados com extratos vegetais e esterco.

O conhecimento das espécies e das variabilidades inter e intra-específicas são fatores basilares para manejar adequadamente as infestações causadas por esses fitopatógenos. No gênero Meloidogyne, a identificação correta das espécies e raças, mediante diagnóstico, permite estabelecer a cultura a ser explorada ou as que poderão compor planos de rotação e até períodos de pousio. Ainda, segundo Eisenback et al. (1981) a resistência desenvolvida em uma cultivar não é necessariamente efetiva contra todas as espécies e raças do nematoide. Vale salientar ainda, que estes resultados são de extrema importância, principalmente, para estas espécies estudadas, pois muitas dessas, notadamente as medicinais, ainda não passaram por um rigoroso programa de melhoramento (Moura, 1997; Charchar \& Moita, 2005).

Segundo Ferraz \& Freitas (2008), o gênero Tagetes, família Asteraceae, conhecido popularmente como cravo de defunto, contém mais de 50 espécies das quais somente seis anuais e três perenes são atualmente cultivadas. Em muitos estudos tem sido demonstrada a eficácia de Tagetes spp. para controlar fitonematoides, havendo um considerável tomo de pesquisas que tem sido conduzido nesta área, sendo a sua maioria indicando que estas plantas são muito eficientes nesta função, especialmente contra espécies de Pratylenchus e Meloidogyne. Tagetes patula, T. erecta e $T$. minuta são as três espécies mais utilizadas no controle de nematoides, sendo que $T$. patula tem se mostrado mais eficiente. Elas são comumente usadas em rotação de culturas, mas em algumas situações funcionam muito bem em consorciação ou mesmo a aplicação de extratos aquosos das plantas, como se verifica em Santos 
e Ruano (1997); Freitas \& Ferraz (2004); Frazener et al., (2007); Gardiano et al., (2009); Ferreira;Silva:Nascimento (2013).

Em razão do aumento expressivo na produção de fruteiras, principalmente goiaba, no estado do Ceará, da importância agrícola do gênero Meloidogyne associado à cultura e causando grandes prejuízos, do controle para tal moléstia ainda não existir, desenvolveu-se este ensaio com o objetivo avaliar a alternativa de controle de $M$. enterolobii com a incorporação de fitomassa de cravo de defunto ao solo.

\section{MATERIAL E MÉTODOS}

Os ensaios deste trabalho foram conduzidos em estufa com cobertura de filme plástico de $150 \mu$ e telado nas laterais com sombrite de $30 \%$, no Assentamento Estrela, distrito Estrela, Município de Barbalha, localizado na região do Cariri cearense, com coordenadas geográficas de latitude de 0716'39" S e longitude de 3915'50" W, no período de janeiro a maio de 2009.

Sabendo-se a identificação correta do patógeno, o qual trata-se do nematoide das galhas pertencente à espécie Meloidogyne enterolobii. O referido patógeno foi identificado no Laboratório Fitonematologia, da Universidade Federal do Ceará, em Fortaleza, a espécie foi identificada pelo método molecular eletroforese de isoenzimas, obtendo-se o fenótipo isoenzimático de esterase, de acordo com Carneiro \& Almeida (2001). Para tanto, uma fêmea era retirada do sistema radicular infectado e macerada, em seguida, adicionada em gel de poliacrilamida; sendo a corrida eletroforética conduzida no sistema horizontal a 80 volts e temperatura de 4 a 8 ㅇ (Carneiro \& Almeida, 2001).

Quanto ao controle alternativo com cravo de defunto, as sementes de cravo de defunto foram semeadas em bandejas de poliestireno expandido de 200 células e mantidas em casa de vegetação, sob controle de umidade para favorecer a germinação. Após a germinação, fez-se uma seleção das melhores mudas, as quais foram transplantadas, em número de cinco, para cada saco de polietileno preto de $11 \times 22 \mathrm{~cm}$, contendo como substrato solo infestado com nematoides em vários estádios de desenvolvimento (galhas, massas de ovos, juvenis). Feito isso, as plantas ficaram se desenvolvendo em ambiente sombreado (30\%), com controle de umidade para um desenvolvimento adequado das mesmas por períodos variáveis de 12, 18, 24 e 30 dias após o transplantio. Passado cada período desses, as cinco plantas de cada saco, eram arrancadas e cortadas com faca em pequenos pedaços e, em seguida, incorporadas ao mesmo substrato e colocadas novamente no saco, onde foram plantadas mudas de tomate 'Santa Clara' com 12 dias após a germinação. Utilizou-se o tomate por ser uma espécie altamente susceptível aos nematóides das galhas.

Passados 35 dias após o transplantio do tomate, faz-se a avaliação final, na qual, eram consideradas as seguintes variáveis: número de galhas, peso fresco da parte aérea e peso fresco do sistema radicular.

O ensaio foi disposto em delineamento inteiramente casualizado (DIC), com cinco repetições e cinco plantas de tomate em cada uma, plantada em solo infestado e com a incorporação da massa verde de cravo de defunto, totalizando 25 vasos/mudas, sendo cinco por cada tratamento, caracterizando assim a unidade experimental. 
O tomateiro (Solanum lycopersicum) 'Santa Clara' foi utilizado como indicador da qualidade do inóculo, em 10 plantas que foram mantidas como repetições e outras 10 cultivadas em solo estéril (testemunha negativa).

Os dados obtidos nesse ensaio foram submetidos à verificação da homogeneidade das variâncias pelo teste de Hartlet, conforme Banzatto \& Kronka (2006). Observada a normalidade dos dados, procedeu-se a análise de variância, a qual foi realizada no programa estatístico Assistat versão 7.4 beta, sendo as variâncias comparadas pelo teste $F$ ao nível de $1 \%$ de probabilidade. A comparação das médias entre os tratamentos fez-se pelo teste de Tukey ao nível de $1 \%$ de probabilidade. Os resultados foram apresentados na forma de tabelas e gráficos.

\section{RESULTADOS E DISCUSSÃO}

Na Tabela 1, estão expostos os dados referentes ao número de galhas em plantas de tomate submetidas aos tratamentos com incorporação de massa fresca de cravo de defunto aos $12,18,24$ e 30 dias após o transplantio.

Tabela 1. Número de galhas de plantas de tomate submetidas aos tratamentos com incorporação de massa fresca de cravo de defunto aos 12, 18, 24 e 30 dias após o transplantio. IFCE - Campus de Sobral. Sobral - CE. 2015.

\begin{tabular}{|c|c|c|c|c|c|c|}
\hline \multirow{2}{*}{ Tratamentos } & \multicolumn{5}{|c|}{ Repetições } & \multirow{2}{*}{ Média } \\
\hline & 1 & 2 & 3 & 4 & 5 & \\
\hline \multicolumn{7}{|c|}{.....................úmero de galhas (galhas/planta)................... } \\
\hline Testemunha $(-)^{1}$ & $312 b$ & $447 a$ & $589 a$ & $631 a$ & $472 a$ & 492,2 \\
\hline 12 dias & $473 a$ & $203 b$ & $205 b$ & $112 b$ & $241 b$ & 246,8 \\
\hline 18 dias & $61 c$ & $68 c$ & $118 \mathrm{c}$ & $78 \mathrm{bc}$ & $97 c$ & 84,4 \\
\hline 24 dias & $97 c$ & $102 c$ & $123 c$ & $142 b$ & $101 c$ & 113 \\
\hline 30 dias & Od & Od & Od & 7c & $9 d$ & 3,2 \\
\hline Testemunha $(+)^{2}$ & Od & Od & Od & Oc & Od & 0 \\
\hline
\end{tabular}

$\left({ }^{1}\right)$ plantas de tomate 'Santa Clara' cultivadas em solo infestado com nematoide das galhas.

$\left(^{2}\right)$ plantas de tomate 'Santa Clara' cultivadas em solo estéril.

De acordo com estes dados, pode-se perceber que a incorporação da matéria verde de cravo de defunto foi bastante eficaz na redução da população de nematoides no solo tratado, diferindo estatisticamente em relação às plantas mantidas como testemunha. Houve redução da população desde a incorporação com 12 dias, contudo, os resultados mais expressivos começaram a aparecer após os 18 dias.

Percebe-se também, ainda na análise da Tabela 1, que nos intervalos de 24 e 30 dias, a incorporação obteve seus picos de inibição da reprodução da população do nematoide, chegando em alguns casos a não observação de galhas nos sistemas radiculares de algumas plantas. Verifica-se em números médios destes dois intervalos uma redução de $88 \%$, em relação à testemunha. Campos et al., (2001), conseguiram redução expressiva na inibição da eclosão de juvenis $\mathrm{J} 2$ de $M$. incognita, superior a $85 \%$, quando estes foram tratados com extratos vegetais e esterco. Estes autores acreditam que no extrato das plantas e no esterco possam existir distintos compostos capazes de afetar a motilidade, a eclosão e morte em diferentes estádios de desenvolvimento dos nematoides. 
Portanto, em vista destes resultados observados, acredita-se que o cultivo sucessivo de cravo de defunto em áreas infestadas por este patógeno, isso principalmente em áreas cultivadas com plantas perenes e a conscientização do produtor em realizar sempre a rotação com esta espécie seja um meio eficiente para a redução populacional, em áreas de cultivo intensivo com hortaliças e plantas ornamentais.

Provavelmente a baixa reprodução dos nematoides ocorreu devido à presença de substâncias bioativas existentes nos exudados radiculares do cravo de defunto (Simões et al., 2003). Tais substâncias possuem efeitos bactericida, inseticida e anti-séptico já comprovados e que poderiam desfavorecer a penetração e/ou o parasitismo do nematoide.

Além disso, a espécie cravo de defunto é citada como antagonista para uso em manejo de solo infestado com Meloidogyne. A ação supressiva sobre fitonematoides é atribuída à presença de compostos nematicidas ' $\alpha$-terthienil-5-(3-buten-1-inil)-2,2'-bithienyl e derivados. A planta atua como armadilha, ou seja, o nematoide penetra mas não consegue completar seu ciclo de parasitismo, o que reduz drasticamente a população do patógeno. Franzener, et al., (2007) verificaram que o extrato aquoso de $T$. patula reduziu em $62,2 \%$ o número de galhas, em $61,5 \%$ o número de juvenis no solo e em $52,8 \%$ o número de ovos nas raízes do tomateiro.

Silva et al., (2006) verificaram redução significativa na população de $M$. incognita, em solo depois da incorporação de resíduos foliares de pimenta de macaco (Piper aduncum). Os mesmo autores verificaram ainda que as plantas que se desenvolveram nesse solo apresentavam-se mais vigorosas.

Constatou-se ainda, a partir de exames minuciosos do sistema radicular, que as plantas cultivadas em solo incorporado com a matéria fresca de cravo de defunto, principalmente nos tratamentos após 18 dias, apesar da quantidade de galhas, estas apresentavam-se pequenas e sem massas de ovos. Isso ficou mais explícito na observação das plantas, pois, apesar de menos desenvolvidas estas maninham certo caráter de vigor, contrastando com as plantas cultivadas em solo infestado.

Segundo Moura (1997) a simples presença de galhas não é fator determinante para susceptibilidade das espécies vegetais ao nematoide das galhas, pois em muitos casos o nematoide parasito induz a formação de galhas, mas não é capaz de se reproduzir ou o faz limitadamente. Ainda para Moura (1997), a presença de galhas indica um aspecto sintomatológico e não deve ser empregado como parâmetro avaliativo de plantas resistentes, pois há casos em que plantas resistentes formam galhas e susceptíveis que não as apresentam.

Partindo-se do pressuposto de que o ciclo de parasitismo dos nematoides do gênero Meloidogyne inicia-se com a penetração de juvenis de segundo estádio (J2) nas raízes da planta e estende-se até a ovoposição, e que o ciclo varia de 25 a 28 dias, em temperatura média de 28 o C (Lordello, 1992; Tihohod, 1993; Ferraz et al., 2010), é possível supor que no ensaio, ora avaliado com temperatura média de $30 \pm 5$ ㅇ C, nas plantas hospedeiras ocorreu com certeza o desenvolvimento de um ciclo reprodutivo completo do nematoide. Assim, o tempo do ensaio de 35 dias, foi suficiente para permitir a análise segura dos resultados de infecção pelo nematoide, o que possibilitou a classificação do parasitismo, conforme se verificaram nas plantas testadas. Isso fica evidente quando se confere a Figura 2 - A, onde mostra uma planta de tomate com apenas 15 dias após a inoculação, e evidenciando muitas galhas em seu sistema radicular, apesar da 
precoce idade. Já na Figura 2 - B, evidencia-se plantas de tomate aos 35 dias após a inoculação, mostrando a capacidade reprodutiva do nematoide.
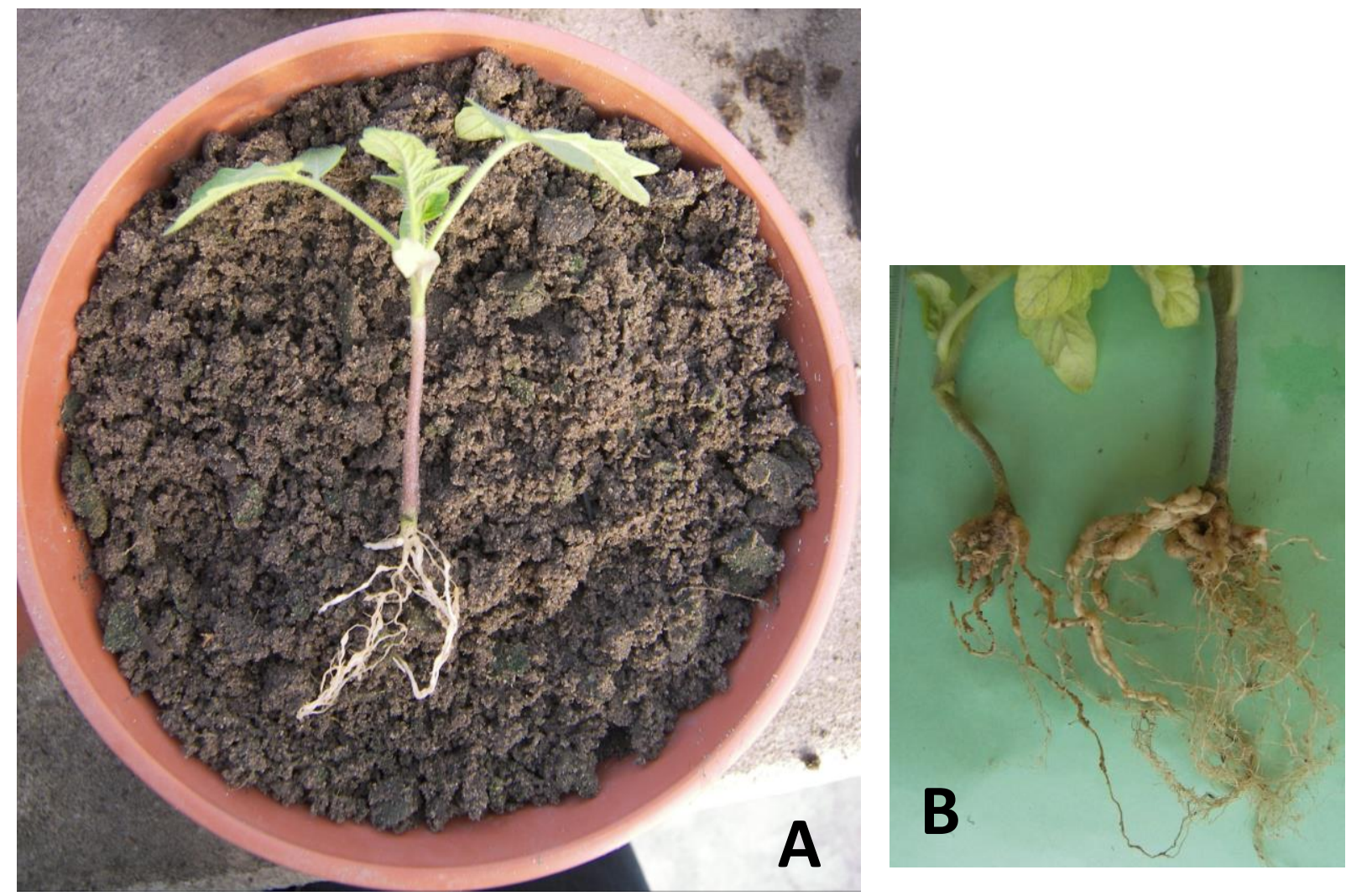

Figura 1. Em A planta de tomate 'Santa Clara' com 15 dias após a inoculação e em B plantas de tomate 'Santa Clara' 35 dias após a inoculação. IFCE- Campus Sobral, Sobral - CE. 2015.

Na Tabela 2, estão expostos os dados referentes ao peso fresco das plantas de tomate submetidas aos tratamentos com incorporação de massa fresca de cravo de defunto aos 12,18 , 24 e 30 dias após o transplantio.

Tabela 2. Peso fresco da parte aérea de plantas de tomate submetidas aos tratamentos com incorporação de massa fresca de cravo de defunto aos 12, 18, 24 e 30 dias após o transplantio. IFCE - Campus de Sobral. Sobral CE. 2015.

\begin{tabular}{|c|c|c|c|c|c|c|}
\hline \multirow{2}{*}{ Tratamentos } & \multicolumn{5}{|c|}{ Repetições } & \multirow{2}{*}{ Média } \\
\hline & 1 & 2 & 3 & 4 & 5 & \\
\hline \multicolumn{7}{|c|}{ 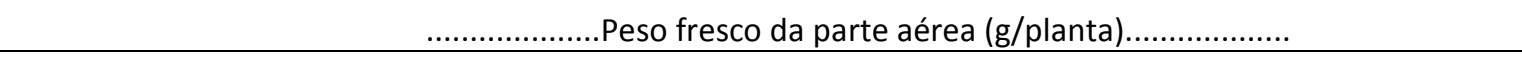 } \\
\hline Testemunha $(-)^{1}$ & $42,57 c$ & $40,36 c$ & $39,85 c$ & $43,65 c$ & $40,00 \mathrm{c}$ & 41,30 \\
\hline 12 dias & $38,20 c$ & $40,12 c$ & $41,58 c$ & $38,65 c$ & $40,2 c$ & 39,80 \\
\hline 18 dias & $39,28 c$ & $45,00 \mathrm{c}$ & $42,15 c$ & $51,24 b$ & $44,18 c$ & 44,40 \\
\hline 24 dias & $53,40 b$ & $48,64 \mathrm{c}$ & $52,00 b$ & $55,41 b$ & $53,14 b$ & 52,50 \\
\hline 30 dias & $52,86 b$ & $60,14 b$ & $55,84 b$ & $53,26 b$ & $58,74 b$ & 56,20 \\
\hline Testemunha $(+)^{2}$ & $95,40 a$ & $102,45 a$ & $86,97 a$ & 98,54 a & $95,20 a$ & 95,70 \\
\hline
\end{tabular}

${ }^{1}$ ) plantas de tomate 'Santa Clara' cultivadas em solo infestado com nematoides das galhas.

$\left(^{2}\right)$ plantas de tomate 'Santa Clara' cultivadas em solo estéril. 
Pela análise da Tabela 2, para as variáveis peso fresco da parte aérea, percebe-se que há uma tendência de comportamento desta variável em relação à anterior, portanto, verifica-se um peso elevado das plantas que foram cultivadas em solo estéril, com média de 95,70 g e uma diminuição significativa em relação às plantas de tomate cultivadas onde foi incorporada a massa verde do cravo de defunto com apenas 12 e 18 dias após o transplantio. Provavelmente isso tenha ocorrido devido a pouca quantidade de massa verde existente nessa idade, portanto, não foi suficiente para provocar um efeito satisfatório na redução da população do nematoide no solo e nas raízes.

Quando se avalia, ainda na Tabela 2, os intervalos maiores de 24 e 30 dias após o transplantio, observam-se que há um aumento no peso fresco das plantas, mostrando que a limitação imposta pelo parasitismo do nematoide ao desenvolvimento normal das plantas está diminuído. Neste caso as plantas apresentavam pesos médios de 52,50 e 56,20 g, respectivamente. Para Campos et al., (2001) os compostos bioativos existentes nas plantas podem ter afetado o desenvolvimento dos nematoides, que seja alterando sua motilidade ou mesmo matando-os.

Para as plantas mantidas como testemunhas negativas, ou seja, aquelas cultivadas em solo infestado e sem tratamento algum, observa-se valor médio do peso menos da metade do peso das plantas testemunhas positivas. Estes dados mostram o caráter devastador do parasitismo deste nematoide.

$\mathrm{Na}$ Tabela 3, estão expostos os dados referentes ao peso fresco dos sistemas radiculares de plantas de tomate submetidas aos tratamentos com incorporação de massa fresca de cravo de defunto aos 12, 18, 24 e 30 dias após o transplantio.

Tabela 3. Peso fresco dos sistemas radiculares de plantas de tomate submetidas aos tratamentos com incorporação de massa fresca de cravo de defunto aos 12, 18, 24 e 30 dias após o transplantio. IFCE - Campus de Sobral. Sobral - CE. 2015.

\begin{tabular}{lcccccc}
\hline \multirow{2}{*}{ Tratamentos } & \multicolumn{5}{c}{ Repetições } & \multirow{2}{*}{ Média } \\
\cline { 2 - 6 } & \multicolumn{7}{c}{1} & 2 & 3 & 4 & 5 & \\
\hline Testemunha $(-)^{1}$ & $21,85 \mathrm{a}$ & $20,15 \mathrm{a}$ & $18,54 \mathrm{a}$ & $17,86 \mathrm{a}$ & $21,00 \mathrm{a}$ & 19,88 \\
12 dias & $13,81 \mathrm{~b}$ & $14,35 \mathrm{~b}$ & $12,78 \mathrm{~b}$ & $12,50 \mathrm{~b}$ & $14,80 \mathrm{~b}$ & 13,64 \\
18 dias & $8,97 \mathrm{c}$ & $8,98 \mathrm{c}$ & $9,87 \mathrm{c}$ & $8,65 \mathrm{c}$ & $8,19 \mathrm{c}$ & 7,33 \\
24 dias & $5,84 \mathrm{~d}$ & $4,57 \mathrm{~d}$ & $6,58 \mathrm{~d}$ & $5,80 \mathrm{~d}$ & $6,00 \mathrm{~d}$ & 5,75 \\
30 dias & $5,60 \mathrm{~d}$ & $5,30 \mathrm{~d}$ & $6,94 \mathrm{~d}$ & $5,55 \mathrm{~d}$ & $5,78 \mathrm{~d}$ & 6,03 \\
Testemunha $(+)^{2}$ & $7,49 \mathrm{~d}$ & $8,89 \mathrm{c}$ & $7,69 \mathrm{~d}$ & $8,45 \mathrm{c}$ & $8,74 \mathrm{c}$ & 8,33 \\
\hline
\end{tabular}

$\left({ }^{1}\right)$ plantas de tomate 'Santa Clara' cultivadas em solo infestado com nematoides das galhas.

( $\left.{ }^{2}\right)$ plantas de tomate 'Santa Clara' cultivadas em solo estéril.

Constata-se, na análise da Tabela 3, que os maiores pesos frescos do sistema radicular foram observados em plantas que foram cultivadas em solo com a menor quantidade de massa fresca de cravo de defunto, sendo estes valores estatisticamente diferentes dos intervalos de 24 e 30 dias. Isso ocorre devido à presença das galhas o que aumenta o peso fresco em virtude da grande quantidade de água existente nas mesmas.

A drástica redução no nível populacional de nematoide pode ser visualizada na Figura $2 \mathrm{~A}$. Ressalta-se ainda que nas plantas advindas dos tratamentos de 18, 24 e 30 dias após a 
incorporação da massa fresca de cravo de defunto, as galhas apresentavam-se isoladas, sem ou com poucas massas de ovos e que as plantas apresentavam satisfatório desenvolvimento.

Provavelmente o efeito dos resíduos orgânicos sobre a redução da população de nematoides pode ser explicado pela liberação de compostos tóxicos formados a partir da decomposição da matéria orgânica e do aumento da população de inimigos naturais. Além disso, a presença de princípios ativos com ação nematicida na fitomassa de cravo de defunto também pode ter acelerado o processo de inibição da eclosão e morte de juvenis infestantes.
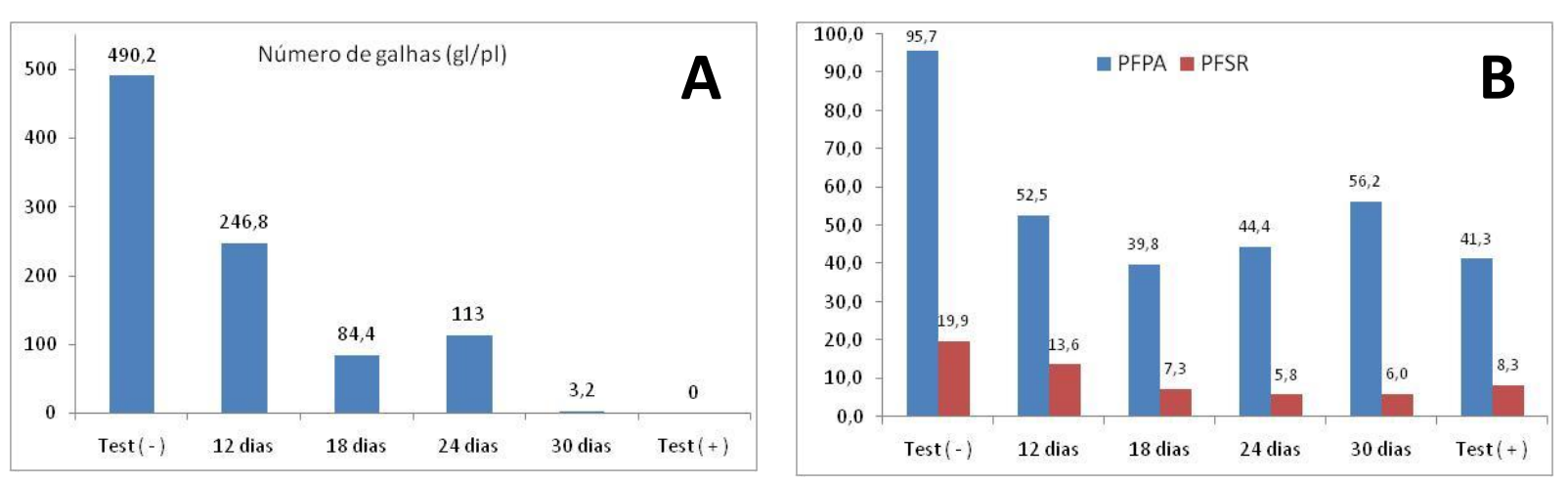

Figura 2. A - Gráfico mostrando a tendência dos valores de número de galhas no sistema radicular e em B - os valores de Peso fresco da parte aérea (PFPA) e do sistema radicular (PFSR) de tomate 'Santa Clara' submetidas aos tratamentos com incorporação de massa fresca de cravo de defunto aos 12, 18, 24 e 30 dias após o transplantio. IFCE - Campus Sobral, Sobral - CE. 2015.

Na Figura 2 (B), nos mostra o comportamento evolutivo das variáveis peso fresco da parte aérea (PFPA) e do sistema radicular (PFSR) de plantas de tomate, em função dos tratamentos com incorporação de massa fresca de cravo de defunto aos 12, 18, 24 e 30 dias após o transplantio.

Visualiza-se, na Figura 2 (B) o desempenho destas variáveis, mais uma vez evidenciado o efeito inibidor do cravo de defunto ao parasitismo do nematoide das galhas $M$. enterolobii.

Com este estudo foi possível constatar mais esta faceta da espécie T. patula, já que a mesma já é amplamente difundida como eficaz no controle de patógenos deste gênero. Outro fato importante foi à forma como se conseguiu estes resultados, os quais não impuseram o emprego de nenhuma tecnologia sofisticada, ou seja, é necessário apenas o plantio da referida espécie no local desejado e o posterior corte e incorporação de sua matéria fresca. Desta forma o produtor precisa elaborar um plano de manejo com rotação de culturas caso sejam anuais ou cultivo consorciado e posterior incorporação da massa verde para que essa possa fazer o efeito desejado.

Como no experimento o melhor resultado de redução populacional do nematoide foi aos 30 dias após o transplantio, acredita-se que em plantio direto no solo das sementes de cravo de defunto seja necessário cerca de 45 dias após a semeadura o momento mais adequado para o corte e a incorporação.

No entanto, são necessários estudos mais estudos que visem aprimorar os resultados obtidos como forma de contribuir ativamente para uma agricultura saudável, sustentável, 
eliminando os efeitos insalubres que homem e o meio ambiente estão expostos com a utilização indiscriminada dos agrotóxicos.

\section{CONCLUSÕES}

Nas condições em que este ensaio foi conduzido e de posse dos resultados observados pode-se concluir que:

- O nematoide das galhas foi identificado como sendo pertencente à espécie Meloidogyne enterolobii;

- A incorporação da massa verde de cravo de defunto ao solo mostrou-se eficiente na redução significativa da população de $M$. enterolobii no solo;

- O corte e a incorporação da massa verde de cravo de defunto aos 30 dias após o transplantio foi o que proporcionou melhor resultado quanto à redução da população de M. enterolobii.

\section{REFERÊNCIAS BIBLIOGRÁFICAS}

1. ADECE. Agência de Desenvolvimento do Ceará. Perfil da produção de Frutas no Brasil em 2013. Disponível em: http://www.adece.ce.gov.br/phocadownload/Agronegocio/perfil_da_ producao_de_frutas_brasil_ceara_2013_frutal.pdf. Acesso em 23 de fevereiro de 2014.

2. BANZATTO, D. A.; KRONKA, S. N. Experimentação Agrícola. Jaboticabal: FUNEP, 386 p. 2006.

3. CAMPOS, V. P.; CAMPOS, J. R.; SILVA, L. H. C. P.; DUTRA, M. R. Manejo de nematoides em hortaliças. In: SILVA, L. H. C. P; CAMPOS, J. R; NOJOSA, G. B. A. Manejo integrado: doenças e pragas em hortaliças. Lavras: UFLA. p.125-158. 2001.

4. CAMPOS, V. P.; SOUZA, J. T.; SOUZA, R. M. Controle de fitonematoides por meio de bactérias. Revisão Anual de Patologia de Plantas, v. 6, p. 285-327. 1998.

5. CARNEIRO, R.M.D.G; ALMEIDA, A. Técnica de eletroforese usada no estudo de enzimas dos nematóides das galhas para identificação de espécies. Nematologia Brasileira. v.25, p 35-44. 2001.

6. CHARCHAR, J. M.; MOITA, A. W. Metodologia para seleção de hortaliças com resistência a nematoides: alface/Meloidogyne spp. Brasília: Embrapa Hortaliças, 8p. 2005.

7. COSTA, M. J. N.; CAMPOS, V. P.; OLIVEIRA, D. F.; PFENNING, L. A. Toxicidade de extratos vegetais e esterco a Meloidogyne incognita. Summa Phytopathologica. Jaboticabal, v. 27, n. 2, p. 245-250. 2001.

8. DIAS, C. R.; SCWAN, A. V.; EZEQUIEL, D. P.; SARMENTO M. C.; FERRAZ, S. Efeito de extratos aquosos de plantas medicinais na sobrevivência de Meloidogyne incognita. Nematologia Brasileira, v. 24, n. 2, p. 202-210. 2000.

9. EISENBACK, J. D.; HIRSCHMANN, H.; SASSER, J. N.; TRIANTAPHYLLOU, A. C. A Guide to the four most common species of root-knot nematodes (Meloidogyne spp.). Internacional Meloidogyne Project - IMP. Raleing - NC, USA. 48p. 1981.

10. FERRAZ, S.; FREITAS, L. G. de. O controle de fitonematoides por plantas antagonistas e produtos naturais. Disponível em: http://www.jcofertilizantes.com.br/pesquisa/pesquisa16o-controle-de-fitonematoides.pdf. Acesso em 23 de fevereiro de 2015. 
11. FERRAZ, S.; FREITAS, L. G.; LOPES, E. A.; DIAS-ARIEIRA, C. R. Manejo sustentável de fitonematoides. Viçosa - MG, Ed: UFV, 306 p. 2010.

12. FERRAZ, S.; FREITAS, L. G. Use of antagonistic plants and natural products. In: CHEN, Z. X.; CHEN, S. Y.; DICKSON, D. W. Nematology advances and perspectives: Nematode Management and Utilization. Beijing: CABI Publishing, p. 931-977. 2004.

13. FERREIRA, I. C. M.; SILVA, G. S. da; NASCIMENTO, F. S.. Efeito de extratos aquosos de espécies de Asteraceae sobre Meloidogyne incognita. Summa phytopathol., Botucatu , v. 39,n. 1,Mar. 2013.

14. FRANZENER, G.; MARTINEZ-FRANZENER, A.S.; STANGARLIN, J.R.; FURLANETTO, C.; SCHWANESTRADA, K.R.F. Proteção de tomateiro a Meloidogyne incognita pelo extrato aquoso de Tagetes patula. Nematologia Brasileira, Brasília, v.31, n.1, p.27-36, 2007.

15. FRANZENER, G.; MARTINEZ-FRANZENER, A. S.; J. R, FURLANETTO, C.; SCHWAN-ESTRADA, R. F. Proteção de tomateiro a Meloidogyne incognita pelo extrato aquoso de Tagetes patula. Nematologia Brasileira, v. 31, p. 27-36. 2000.

16. FREITAS, L. G.; OLIVEIRA, R. D. L.; FERRAZ, S. Introdução à Nematologia. 1a ed. (2a reimpressão) Viçosa - MG: Editora UFV, 84p. 2004. (Cadernos Didáticos - 58).

17. GARDIANO, C.G., FERRAZ, S., LOPES, E. A., FERREIRA, P. A.; AMORA, D.X.; FREITAS, L.G. Avaliação de extratos aquosos de várias espécies vegetais, aplicados ao solo, sobre Meloidogyne javanica (Treub, 1885) Chitwood, 1949. Semina: Ciências Agrárias, Londrina, v.30, v.3, p.551-556, 2009.

18. LORDELLO, L. G. E. Nematoides das plantas cultivadas. 9a ed. São Paulo. Nobel. 356p. 1992.

19. MANSO, E. C.; VILARDI TENENTE, R. C.; FERRAZ, L. C. B.; OlIVEIRA, R. S; MESQUITA, R. Catálogo de nematoides fitoparasitos encontrados associados a diferentes tipos de plantas no Brasil. EMBRAPA. Centro Nacional de Pesquisa de Recursos Genéticos e Biotecnologia. Brasília. 488p. 1994.

20. MOREIRA, F. J. C.; SANTOS, C. D. G.; INNECCO, R. Eclosão e mortalidade de juvenis J2 de Meloidogyne incognita, raça 2 em óleos essenciais. Revista Ciência Agronômica, v. 40, n. 3, p. 441-448. 2009.

21. MOURA, R. M. O gênero Meloidogyne e a meloidoginose. In: Revisão Anual de Proteção de Plantas. 5:281-315. 1997.

22. NEVES, W. S.; FREITAS, L. G.; DALLEMOLE-GIARETTA, R.; FABRY, C. F. S.; COUTINHO, M. M.; DHINGRA, O. D.; FERRAZ, S.; DEMUNER, A. J. Atividade de extratos de alho (Allium sativum), mostarda (Brassica campestris) e pimenta malagueta (Capsicum frutescens) sobre a eclosão de juvenis Meloidogyne javanica. Nematologia Brasileira, v. 29, n. 2, p. 273-278. 2005.

23. SANTOS, M. A. dos; RUANO, O. Reação de plantas usadas como adubos verdes a Meloidogyne incognita raça 3 e M. javanica. Nematologia Brasileira, Piracicaba, v. 11. p. 185-196, 1997.

24. SILVA, G. S.; PEREIRA, A, L.; BASTOS, C. N.; MENDONÇA, V. C. M. Efeito da incorporação de resíduos foliares de Piper aduncum ao solo sobre o parasitismo de Meloidogyne incognita em tomateiro. Nematologia Brasileira, v. 30, n. 2, p. 219-222. 2006.

25. SIMÕES, C. M. O.; SCHENKEL, E. P.; GOSMANN, G.; MELLO, J. C. P.; MENTZ, L. A.; PETROVICK, P. R. Farmacognosia: da planta ao medicamento. 5o ed. Porto Alegre, UFRGS. Florianópolis, 
UFSC. 1104p. 2003.

26. TIHOHOD, D. Nematologia Agrícola Aplicada. Jaboticabal: FUNEP, 372p. 1993. 